\title{
28 Resarach Soure \\ Intestinal Absorption of Geniposide and Inhibition of Transporter-P-GP Across the Caco-2 Monolayer
}

\section{Yanhong Bu}

Anhui University of Traditional Chinese Medicine

hong wu ( $\nabla$ wuhongprof@aliyun.com )

Anhui University of Traditional Chinese Medicine

MingHui Sun

Anhui University of Traditional Chinese Medicine

Heng Zhang

Anhui University of Traditional Chinese Medicine

\section{Ran Deng}

Anhui University of Traditional Chinese Medicine

Yan Wang

Anhui University of Traditional Chinese Medicine

Research article

Keywords: Caco-2 cells, Geniposide, Intestinal absorption, P-glycoprotein

Posted Date: September 24th, 2020

DOI: https://doi.org/10.21203/rs.3.rs-61518/v1

License: (c) (i) This work is licensed under a Creative Commons Attribution 4.0 International License.

Read Full License 


\section{Abstract}

Background: Geniposide (GE) is the main bioactive component of Gardenia jasminoides Ellis, which has many pharmacological effects, such as anti-inflammatory, anti-oxidation, and anti-angiogenesis. GE has low absolute bioavailability after oral administration, and speculated that GE might have an effect on Pglycoprotein (P-gp) described in our previous study. However, intestinal absorption characteristics involved in the Caco-2 cells of GE are still unknown. Therefore, we aimed to investigate absorption mechanisms of GE and the effects on P-gp.

Methods: By establishing the Caco-2 cells model and HPLC method, bidirectional transport of GE in the different conditions and the presence of P-gp inhibitors $₫$ verapamil were conducted to observe its absorption mechanisms. Transport assays of digoxin, a P-gp substrate, were also performed in the presence of GE or verapamil. The effects of GE on the function and expression of P-gp were analyzed by flow cytometry and Western blot using rhodamine-123 (rho-123) and the antibody, respectively.

Results: Both absorption and secretion of GE were positively correlated with concentration and time at Caco-2 cell monolayer. The Papp of bidirectional transport was decreased in low temperature and the Papp(BL-AP) of GE decreased significantly in the presence of verapamil. Meanwhile, the ER value was higher than 1.5. In addition, in the bidirectional transport of digoxin, the values of Papp(BL-AP) and ER decreased significantly in the presence of GE, just like verapamil. GE increased the intracellular accumulation of rho-123 and also have a significant decrease on P-gp expression.

Conclusion: Transepithelial transport mechanism of GE in Caco-2 cell monolayer is mainly passive diffusion and P-gp mediated active transportation. GE was a potential inhibitor of P-gp, can inhibit transport of digoxin and the function and expression of P-gp.

\section{Background}

Geniposide (GE), an iridoid glycoside compound, is the major active component of Gardenia jasminoides Ellis fruit, which is traditionally used for its antiphlogistic and antipyretic effects in many Asian countries [1]. In recent years, the pharmacological effects of geniposide on antioxidation and angiogenesis have been gradually studied ${ }^{[2,3]}$. The development of new drugs and the wide application of drugs and herbs resulted in the potential of drug-drug interaction (DDI) have been noticed ${ }^{[4]}$. Membrane transporters, such as P-glycoprotein (P-gp), as a major barriers limiting oral drug delivery, play a key role in DDI, which can affect oral bioavailability, regulate the absorption, distribution and excretion of a large number of foreign substances ${ }^{[5]}$. Therefore, P-gp-related interactions have important clinical impacts and it is critical to understand which drugs are inducers or inhibitors of P-gp to minimize or avoid adverse interactions.

The pharmacokinetics, bioavailability and tissue distribution of GE has been reported, and low oral bioavailability limits its clinical application ${ }^{[6,7]}$. The study of intestinal absorption of drugs can provide important informations such as absorption mechanism, absorption site and factors affecting absorption, 
and provide reference for drug development ${ }^{[8,9]}$. It is very important to absorb the blood from gastrointestinal tract to make the chemical components with pharmacological activity exert biological effects. In addition, some studies on intestinal absorption of other iridoid glycosides in vivo or in vitro showed that these compounds interacted with P-gp probably ${ }^{[10,11]}$. Therefore, it is necessary to study the intestinal absorption characteristics after oral administration and the factors which may effect absorption.

In order to reveal the influencing factors and mechanisms of oral drug absorption, researchers have established a variety of models. Cell model is an important method for evaluating drug absorption in vitro and the human colon adenocarcinoma cell line (Caco-2) cell has become the most common characterized cell-based model in predicting the absorption and transport potential of compounds ${ }^{[12]}$. The Caco-2 cell line has a number of biophysical and biochemical characteristics, which are similar to the features of a normal intestinal absorptive cell. For example, the expression levels of intestinal specific hydrolase, P-gp and multidrug resistance associated protein (MRP2) were the same as those in normal jejunal epithelial cells ${ }^{[13,14]}$. Drug transporters distributed in cell membranes are often used to study the mechanism of vector-mediated uptake and efflux ${ }^{[15]}$. The transport activity of P-gp will be induced or inhibited by some substrate drugs with different interaction, such as erythromycin, cyclosporine, verapamil, and rifampicin, which may affect the absorption and combination of drugs ${ }^{[16]}$. The increase of P-gp activity may lead to drug resistance and may affect the pharmacokinetic absorption. Conversely, the presence of an P-gp inhibitor may increase the bioavailability of substrate drugs in the intestine and has an impact on the clinical safety of the selected drug.

The aim of the present study was to investigate the intestinal absorption characteristics of GE by utilizing the Caco-2 cells model. In addition, the bidirectional transport of digoxin in the Caco-2 cell model was explored in order to estimate potential drug interactions. The activity of P-gp was evaluated by transport of rhodamine 123 (rho-123), as reported in other studies. Digoxin and rho-123 were used as a substrate and verapamil as a inhibitor of P-gp.

\section{Methods}

\section{Materials}

Caco-2 cell line was donated by college of pharmacy, Anhui University of Chinese Medicine; Fetal bovine serum (FBS), Dulbecco's modified Eagle's medium (DMEM), Non-essential amino acids (NEAA), 0.25\% trypsin/1 m M EDTA, antibiotic-antimycotic mixture (10,000 U/ml penicillin, 10,000 I g/ml streptomycin) were purchased from Thermo Scientific Co. (Hudson, NH, USA); Hank's Balanced Salt Solution(HBSS), Dimethyl sulfoxide (DMSO), Rhodamine-123 (Rho-123) were purchased from Beijing Solarbio Science \& Technology Co., Ltd; Verapamil (VER) were purchased from Sigma Chemical Co. (St. Louis, MO, United States); Geniposide is a white powder with $98 \%$ purity (determined by UPLC); All other chemicals used in this study were of analytical grade from commercial sources. Anti-P Glycoprotein antibody [EPR 10364- 
57] ab170904, Anti-P Glycoprotein antibody [UIC2] (Phycoerythrin) ab93590 was purchased from Abcam(Cambridge, United Kingdom). Chromatographic separation was performed on a C18 column, Luna C18 100A, $250 \times 4.60 \mathrm{~mm}$ by using the Agilent 1260 HPLC system (Agilent Technologies, CA,USA).

\section{Cell culture and establishment of transwell model}

The Caco-2 cell line was cultured in a DMEM medium containing $10 \% \mathrm{FBS}, 1 \%$ non-essential amino acids, $1 \%$ L-glutamic acid and $1 \%$ Penicillin-Streptomycin Solution(100x) at $37{ }^{\circ} \mathrm{C}$ in a $5 \% \mathrm{CO}_{2}$ incubator. Caco-2 cells are in the shape of paving stone-like and grow in clusters. The cells were $30-60$ generations for this experiment, which were in logarithmic growth phase.

The cells were seeded onto polycarbonate membrane (transwell inserts) at a density of $1 \times 10^{5}$ /well for $21 \mathrm{~d}$ to establish the transport model in vitro. Cell suspension was added to the apical (AP) of transwell chamber, and medium was added to the basolateral (BL). The medium was changed once every two days after inoculation, and every day after a week. The cells were cultured for 21 to $23 \mathrm{~d}$ to form a cell monolayer. Cell morphology, transepithelial electrical resistance (TEER) and cell polarity were used to determine the integrity of cell monolayer for subsequent transport experiments.

\section{Evaluation of transwell model Cell morphology}

The polycarbonate membrane at the bottom of the chamber was cut off and fixed in $2.5 \%$ glutaraldehyde overnight. After washing with PBS, cells were immobilized in $1 \%$ osmium acid, dehydrated and embedded in ethanol and propylene oxide. After immersion, the cells were transferred to a special embedding board and incubated in oven. The slice was sliced to a thickness of $70 \mathrm{~nm}$. After being stained, the images were observed and recorded under transmission electron microscope.

\section{Transepithelial Electrical Resistance}

Caco-2 cells were cultured in transwell chamber and measured on the $3,6,9,12,15,18$ and $21 \mathrm{~d}$. Before the measurement, the electrode was immersed in $70 \%$ ethanol for 15 minutes, and air-dried. During the measurement, the short electrode was inserted into the apical and the long electrode into the basolateral. Note that the electrodes should be inserted vertically and that the ends of the electrodes should not touch the bottom of the transwell chamber. Each chamber was measured three times at random, and the results were recorded as Rt. The results of blank chamber were recorded as R0.The TEER value is calculated according to the formula: TEER $=(\mathrm{Rt}-\mathrm{R} 0) \times \mathrm{S}$ ( $\mathrm{S}$ is the effective membrane area of the cell. Generally, TEER values largrer than $500 \Omega \cdot \mathrm{cm}^{2}$ can be regarded as single layer compact and complete ${ }^{[17]}$. The higher the TEER value, the denser the monolayer is, generally not more than $1000 \Omega \cdot \mathrm{cm}^{2}$.

\section{Cell polarity}


When cells grew in transwell chamber for 4, 7, 15 and $21 \mathrm{~d}$, the cell monolayer was gently washed with PBS and incubated at $37^{\circ} \mathrm{C}$ for 30 min. Alkaline phosphatase (AKP) activity of AP and BL side was measured by kit. The OD value was measured by a microplate reader at $520 \mathrm{~nm}$. AKP activity $=A$ (measurement) / A (standard) $\times$ standard phenol content $(0.005 \mathrm{mg}) \times 100 \mathrm{~mL} / 0.05 \mathrm{~mL}{ }^{[18]}$.

\section{Cytotoxicity assay}

In order to select the appropriate concentration, the toxicity of the test substances at different concentrations to Caco- 2 cells was determined by IC50 and MTT assay. Cells were seeded in 96-well plates and incubated overnight after cell counting ( $10^{4}$ cells/well). Different concentrations of GE (100, $200,300,400,500,600,700,800,900$ and $1000 \mu \mathrm{g} / \mathrm{mL}$ ) were added to the experimental group and incubated at $37^{\circ} \mathrm{C}$ for 24 hours. Thereafter, $10 \mu \mathrm{L}$ MTT was added to each well and incubated at $37^{\circ} \mathrm{C}$ for $4 \mathrm{~h}$. After incubation period, the cell medium was removed and the formed formazan crystals dissolved in $100 \%$ DMSO. The 96-well plate was shaken for $15 \mathrm{~min}$ at room temperature in the dark and then the absorbance was measured at $520 \mathrm{~nm}$. The IC50 value was calculated by Graphpad Prism software (version 6.0).

In order to determine the concentration of GE, Caco-2 cells were incubated with a series of GE concentrations $(1,2,5,10,25,50,100,200 \mu \mathrm{g} / \mathrm{mL})$ at $37^{\circ} \mathrm{C}$ with different durations $(6,12,24,48 \mathrm{~h})$. The survival rate of Caco-2 cells at different concentrations of GE was examined. The cell survival rate was calculated by the following formula: Cell viability $=(O D$ the xperimental group $-O D$ the blank group) $/(O D$ the negative control group - OD the blank group) $\times 100 \%$.

\section{HPLC analytical methods}

Chromatographic separation was performed on a C18 column (Luna C18 100A, $250 \times 4.60 \mathrm{~mm}$ ) by the Agilent 1260 HPLC system (Agilent Technologies, CA,USA). The GE sample was analyzed by acetonitrilewater $(15: 85)$ at $25^{\circ} \mathrm{C}$ and flow rate was $1.0 \mathrm{~mL} / \mathrm{min}$. The injection volume was $10 \mu \mathrm{L}$ and detection wavelength was $238 \mathrm{~nm}$. For digoxin samples, the mobile phase was acetonitrile-water (35:65) and detection at $220 \mathrm{~nm}$.

\section{Bidirectional transport experiments}

Caco-2 cells formed integrated and tight monolayers after 21d differentiation, which used for transport experiments. In the AP-BL transport experiment (the absorptive direction), $0.5 \mathrm{~mL}$ drug solutions of GE $(10,25,50,100 \mu \mathrm{g} / \mathrm{mL})$ or in the presence of verapamil $(100 \mu \mathrm{M})$ were added to the apical chamber (donor), $1.5 \mathrm{~mL}$ blank HBSS was added to the basolateral chamber (receiver), and then samples $(200 \mu \mathrm{L})$ were collected from the basolateral chamber at different time points, 30, 60, 90, 120,150, and $180 \mathrm{~min}$. In the BL-AP transport experiment (the secretory direction), $1.5 \mathrm{~mL}$ GE solutions $(10,25,50,100 \mu \mathrm{g} / \mathrm{mL})$ or in the presence of verapamil $(100 \mu \mathrm{M})$ were added to the basolateral chamber (donor), $0.5 \mathrm{~mL}$ blank HBSS was added to the apical chamber (receiver), and then samples $(200 \mu \mathrm{L})$ were collected from the apical chamber at different time points. 
For digoxin assay, bidirectional transport experiments in the presence or absence of verapamil $(100 \mu \mathrm{M})$ or $\mathrm{GE}(25,50,100 \mu \mathrm{g} / \mathrm{mL})$ was performed by digoxin $(10 \mu \mathrm{M})$, as mentioned above. The samples were centrifuged at high speed (16 $000 \mathrm{rpm}, 20 \mathrm{~min}$ ). The content of GE was analyzed by HPLC.

The apparent permeability coefficient (Papp) was calculated by formula (1), and the efflux ratio (ER) was calculated by formula (2). Papp $=(\mathrm{dQ} / \mathrm{dt}) /(\mathrm{A} \times \mathrm{CO})(1)$, where $\mathrm{dQ} / \mathrm{dt}$ is the transmission rate of GE per unit time, $A$ is the surface area of Caco-2 monolayer $\left(0.03 \mathrm{~cm}^{2}\right)$, and $\mathrm{CO}$ is the initial drug concentration on the donor side. $E R=\operatorname{Papp}(\mathrm{BL}-\mathrm{AP}) / \mathrm{Papp}(\mathrm{AP}-\mathrm{BL})(2)^{[19]}$.

\section{Flow cytometry analysis}

The efflux function of P-gp was performed by rho-123 accumulation and efflux using flow cytometry. The transport activity of P-gp has two phases: accumulation phase and efflux phase. In the accumulation phase, verapamil was used as a P-gp inhibitor to block P-gp activity and rho-123 accumulated in cells. In the efflux phase, the P-gp inhibitor was removed and the high glucose medium was added as an energy substance to re-establish the P-gp energy-dependent efflux phase, and rho-123 flows out of the cell.

Accumulation phase: after digestion of the cell suspension, Caco-2 cells were counted at $5 \times 10^{5}$ cells $/ \mathrm{mL}$, centrifuged (1000 rpm, $5 \mathrm{~min}$ ) and suspended in medium containing 10\% FBS, rho-123 (5 $\mu \mathrm{M})$ and verapamil $(100 \mu \mathrm{M})$. The fluorescent substrates accumulated in the cells durning incubation at $37^{\circ} \mathrm{C}$ for $1 \mathrm{~h}$. Efflux phase: thereafter, it was centrifuged $\left(4^{\circ} \mathrm{C}, 1000 \mathrm{rpm}, 5 \mathrm{~min}\right)$ and washed twice with ice-cold PBS containing $10 \%$ FBS. The cells were resuspended in high glucose medium containing various concentrations of GE and incubated at $37^{\circ} \mathrm{C}$ for $45 \mathrm{~min}$. After rho-123 effluxed, it was washed twice with ice-cold PBS containing 10\% FBS and resuspended in ice-cold PBS for analysis of flow cytometry.

The expression of P-gp on Caco-2 cell membrane was also analyzed by flow cytometry. Caco-2 cells were inoculated into six-well plates with $5 \times 10^{5} \mathrm{cell} / \mathrm{mL}$, and fused into monolayer cells. Verapamil $(100 \mu \mathrm{M})$ and $\operatorname{GE}(25,50,100 \mu \mathrm{g} / \mathrm{mL})$ were administered separately and cultured for $24 \mathrm{~h}$. Subsequently, the cells were washed twice with PBS and digested with $0.25 \%$ trypsin/1 mM EDTA to obtain cell suspension. After centrifugation (1000 rpm, $5 \mathrm{~min}$ ), the cells were suspended in PBS buffer containing 10\% FBS, P-gp antibody [UIC2] (Phycoerythrin). Then, the cells were incubated at $37^{\circ} \mathrm{C}$ for $30 \mathrm{~min}$ in the dark, suspended in ice-cold PBS and stored on ice until analysis of flow cytometry.

\section{Immunofluorescence}

The accumulation of rho-123 in Caco-2 cells was detected by immunofluorescence to evaluate the efflux function of P-gp. Caco-2 cells were plated in six-well plates at $5 \times 10^{5}$ cells $/ \mathrm{mL}$. The cells were then exposed to rho-123 $(5 \mu \mathrm{M})$ and verapamil $(100 \mu \mathrm{M})$ for $1 \mathrm{~h}$. After the accumulation period, the cells were washed twice with PBS and were administered with high glucose medium containing different concentrations of GE, followed by incubation at $37^{\circ} \mathrm{C}$ for $1 \mathrm{~h}$. Then, the cells was washed twice with PBS and observed in a fluorescence microscope.

\section{Western blot}


Caco-2 cells were inoculated into six-well plates with $5 \times 105 \mathrm{cell} / \mathrm{mL}$. After cell fusion, the cells were cultured in medium containing or without GE $(25,50,100 \mu \mathrm{g} / \mathrm{mL})$ and verapamil $(100 \mu \mathrm{M})$ for $24 \mathrm{~h}$. The cells were fully lysed by $300 \mu \mathrm{L}$ lysate (RIPA lysate mixed with PMSF protease inhibitor 100:1 mixed) per pore. The cells were scraped and crushed by ultrasound. The supernatant was centrifuged at $12000 \mathrm{rpm}$ for $20 \mathrm{~min}$ and stored at $-80^{\circ} \mathrm{C}$ until analysis. BCA protein quantitative kit was used to determine protein concentration and ensured the same sample concentration. The proteins were separated by SDS-PAGE and transferred to PVDF membrane by electrophoresis. After that, it was blocked with $5 \%$ skim milk for 2 hours at room temperature, and the primary antibody $(1: 2500)$ was incubated at $4{ }^{\circ} \mathrm{C}$ overnight after washing with TBST. Finally, the secondary antibody was incubated for $2 \mathrm{~h}$ and detected by the ECL luminescent liquid. Band density was measured using Image $\mathrm{J}$ analytical software (National Institutes of Health, Bethesda, MD). The relative expression levels of target proteins are shown by the density ratio to GAPDH internal control or to unphosphorylated total protein in the same sample.

\section{Results}

\section{Evaluation of transwell chamber model}

Three evaluation indexes (cell morphology, TEER, cell polarity) are employed to evaluate the results. After $21 \mathrm{~d}$, there was a layer of microvilli structure perpendicular to the surface of the cell monolayer under transmission electron microscopy, showing finger-like, incomplete and round shapes (Fig.1A). In addition, the tight junction structure between cells can be clearly seen (Fig.1B, C). The TEER increased rapidly in the previous week. After $9 \mathrm{~d}$, the cells fused and the cells showed small intestinal epithelial differentiation. At 18-21d, the resistance reached the plateau stage, and the TEER value is greater than $500 \Omega \cdot \mathrm{cm}^{2}$, indicating a compact and complete monolayer was formed, which meets the experimental requirements (Fig.1D). The AKP activity of AP side increased with time, and the BL side is almost unchanged. At 21d, the activity of AP side was 3.22-fold than that of BL side (Fig.1E). It is proved that the distribution of AKP is very asymmetric, indicated that the cells have polarized at this time, and the Caco-2 cell monolayer has been successfully constructed.

\section{Cytotoxicity assay}

The cytotoxicity and cell viability of GE to Caco-2 cells screened by MTT is shown in the Fig 2. The survival rate of Caco-2 was $100 \%$ at $0-100 \mu \mathrm{g} / \mathrm{mL}$ GE and the IC50 was $236 \mu \mathrm{g} / \mathrm{mL}$, indicating GE exhibited no toxicity on Caco-2 cells at $0-100 \mu \mathrm{g} / \mathrm{mL}$ (Fig.2A). In addition, the cell viability was significantly decreased at $200 \mu \mathrm{g} / \mathrm{mL}$ based on the results of cell viability $(P<0.01)$ (Fig.2B). Therefore, the concentration for subsequent experiments were selected from 0-100 $\mu \mathrm{g} / \mathrm{mL}$.

\section{Effects of time and concerntration on transport of GE}

The time-dependent curve of transported amount with different concentrations in Caco-2 cell model is shown in Fig.3. In AP-BL and BL-AP, the transport amount of each concentration increased approximately linearly in 90 min. After 90 minutes, the curve gradually flattened (Fig3A, B). As shown in Fig 3C, Papp (AP-BL) and Papp (BL-AP) were positively correlated with the concentration. The results showed that 
transport of GE was driven by concentration gradient in a concentration dependent manner, and passive diffusion is the one of transport mechanism at the two sites. In addition, the ER values at different concentrations were higher than 1.5 indicating that the transport of GE was likely to be mediated by efflux transporters. So we studied the effects of temperature and specific inhibitors in the following experiments.

\section{Effects of temperature and P-gp inhibitor on transport of GE}

Low temperature can reduce the activity of proteins involved in the activity transport, suggesting that transporters are involved in the transport of GE. Compared with $37^{\circ} \mathrm{C}$, the Papp (BL-AP) of GE at $4{ }^{\circ} \mathrm{C}$ decreased significantly $(P<0.05)$ (Fig.4A). No significant different of the Papp (AP-BL) was observed at different temperature. As shown in Fig 4B, in the presence of verapamil, a P-gp inhibitor, significantly reduced the efflux of GE, as Papp (BL-AP) decreased from $(4.59 \pm 0.06) \times 10^{-6} \mathrm{~cm} / \mathrm{s}$ to $(1.75 \pm 0.11) \times 10^{-6}$ $\mathrm{cm} / \mathrm{s}(P<0.05)$. This confirmed that $\mathrm{P}$-gp was involved in the transport of $\mathrm{GE}$ and active transportation is another transport mechanism of GE in Caco-2 cells.

\section{Effects of GE on the P-gp mediated transport of digoxin}

The transport function of P-gp was evalued by measuring the transepithelial transport of digoxin across Caco-2 cell. The bilateral Papp values and the ER values of digoxin for GE and verapamil are summarized in Table 1. Digoxin, a classical P-gp substrate, has the ER value of 3.40, which was higher than 2.0. In the presence of verapamil, the Papp (BL-AP) of digoxin decreased significantly to $(7.55 \pm 0.09) \times 10^{-6} \mathrm{~cm} / \mathrm{s}$ $(P<0.05)$, indicating that verapamil was qualified as a positive control. Similarly, different concentrations of GE can reduce the P-gp-mediated digoxin efflux, resulting in the decrease of the Papp (BL-AP) of digoxin $(P<0.05, P<0.01)$. In addition, different concentration of $\mathrm{GE}$ reduced the ER values of digoxin to $1.57,1.59$ and 1.46 , respectively.

\section{Effects of GE on the efflux function of P-gp}

As shown in Fig.5A, different concentration of GE decreased rho-123 efflux and increased intracellular accumulation of rho-123 compared with the control group $(P<0.01)$. Compared with the control group, the fluorescence intensity of rho-123 in GE group increased by $20.0 \%, 31.4 \%(P<0.05)$ and $44.1 \%(P<0.01)$ respectively (Fig.5B), which are consistent with the results of flow cytometry. These results indicated that GE inhibited the efflux function of P-gp in Caco-2 monolayers.

\section{Effects of GE on the expression of P-gp}

As shown in Fig.6, the expression of P-gp in the presence of GE was significantly decreased compared with the control group $(P<0.01)$. Western blot analysis further showed that $\mathrm{GE}$ could inhibit the expression of $\mathrm{P}-\mathrm{gp}(P<0.01)$.

\section{Discussion}


Good oral absorption is a prerequisite for new drug screening, but there are many factors that affect oral absorption, including drug solubility and gastrointestinal permeability. However, it is relatively complicated to predict oral absorption in humans, especially in the early stages of drug development. Intestinal absorption kinetics is one of the important factors determining the bioavailability of oral drugs, and plays an important role in the development and evaluation of oral preparations for traditional Chinese medicine. As the main active component of Gardenia jasminoides Ellis, the study of transport characteristics is an urgent need to clarify the intestinal absorption of GE.

Caco-2 model is considered to be an effective screening method for predicting drug absorption in the intestine ${ }^{[20]}$. It has been widely used in the study of traditional Chinese medicine, with the focus on flavonoids, alkaloids and saponins ${ }^{[21,22]}$. In this study, Caco-2 cell model was used to explore the transport mechanism of GE, because of their good at simulating the human intestinal environment. Bidirectional transport experiments showned that GE was time and concentration dependent in the directionsa of AP-BL and BL-AP (Fig. 3). This indicated that the transport of GE was driven by a concentration gradient, and passive diffusion represents the transport mechanism for GE on both sites. In addition, we investigated the effects of temperature and transporters because of the ER value is greater than 1.5 , which indicates that the transport process may be mediated by transporters. The transporters is a transport protein that exists on the cell membrane and only has biological activity at a appropriate temperature conditions. Therefore, the transporters mediated transport is particularly sensitive to temperature. The results showed that low temperature $\left(4^{\circ} \mathrm{C}\right)$ did inhibit the activity of transporters, resulting in the decrease of Papp value in two directions, and the BL-AP direction was statistically significant (Fig. 4A). In order to exclude the decrease of Papp value caused by crystallization of GE in water at low temperature, which results in the decrease of the actual concentration of GE in the culture system, the effect of P-gp specific inhibitor-verapamil was investigated to determine the transport characteristics of GE (Fig. 4B). Some studies indicated that a higher effect of P-gp inhibitors existed on the secretory pathway compared with the absorptive pathway ${ }^{[23,24]}$. In the presence of verapamil, Papp (AP-BL) increased and Papp (BL-AP) decreased significantly, which indicated that P-gp was participate in the transport of GE in Caco-2 cells and further proved that active transportation is another transport mechanism.

In Caco-2 cell model, we usually use Papp to evaluate the degree of absorption, and a large number of studies on transport mechanism have summarized the following laws: Papp is higher than $1 \times 10^{-5} \mathrm{~cm} / \mathrm{s}$, compounds have good absorption properties, while Papp is less than $1 \times 10^{-6} \mathrm{~cm} / \mathrm{s}$, compounds have low absorption. Compounds with Papp between $1 \times 10^{-6}$ and $1 \times 10^{-5} \mathrm{~cm} / \mathrm{s}$ are considered to have moderate absorption ${ }^{[25]}$. The Papp value of GE ranged from $(1.89 \pm 0.03)$ to $(2.46 \pm 0.05) \times 10^{-6} \mathrm{~cm} / \mathrm{s}$, which indicated GE was absorbed moderately according to the internationally accepted standard. In brief, the in vivo processing of drug is complex and additional research is needed to explain the low oral bioavailability. 
In recent years, protein-mediated drug efflux has attracted much attention. Many transporters are expressed on the membrane of intestinal epithelial cells, among which extroverts (efflux proteins) can actively reverse pump substrates out of the cells, reduce the concentration of intracellular substrates, and reduce drug absorption [26]. In addition, the efflux protein expressed on the cell surface acts as a selective barrier to prevent drugs from entering the intestine, which is the main factor leading to multidrug resistance ${ }^{[27]}$. P-gp and MRP2 are highly expressed in the brush border of intestinal mucosal epithelial cells, which have been widely studied. Among them, P-gp plays an important role in drug interactions because of its broad substrate specificity and potential impact on the oral bioavailability of substrate drugs. Therefore, inhibition or induction of P-gp can lead to drug interactions mediated by P-gp, resulting in increased adverse reactions or improper substrate drug treatment. Many studies have shown that the DDI associated with P-gp are occurring frequently ${ }^{[28]}$. Therefore, P-gp-related interactions have important clinical impacts and it is critical to understand which drugs are inducers or inhibitors of P-gp to minimize or avoid adverse interactions.

The previous research of our group compared pharmacokinetics after oral administration of GE in normal rats and adjuvant-induced arthritis (AA) rats by UPLC-MS/MS, and the results showed that there were significant differences in the groups between the normal and AA rats in pharmacokinetics parameters ${ }^{[29]}$. It is noticeable that rheumatoid arthritis (RA) and AA, a state of chronic inflammatory, can increase the plasma concentration of p-gp substrate drugs. This experiment verified that the GE plasma concentrations of AA rats were all higher than normal rats at most monitoring time points. Therefore, it is reasonable to speculate that GE may may interact with P-gp, which has the potential to reverse the activity of transport protein. Herein, to address whether GE is a potential inhibitor of P-gp in Caco-2 cell monolayers, efflux transport assays of P-gp substrate, digoxin, and the efflux function and expression of P-gp were performed in the presence of GE.

Different drugs as P-gp substrates (digoxin and rho-123) and P-gp inhibitors (verapamil) were used to evaluate the effect of GE on P-gp. Digoxin is a classical P-gp substrate and its high permeability has been proved in experiments (Table 1). P-gp in intestinal tract can transport digoxin from intestinal epithelial cells to intestinal cavity, and reduce its bioavailability and plasma concentration. Rho-123 is a fluorescent substrate widely used to evaluate the function of P-gp, because it can effectively bind to P-gp-mediated transport inhibitors, and the accumulation in cells can be determined by comparing the fluorescence intensity. Although verapamil was considered to be a relatively weak P-gp inhibitor compared with other P-gp inhibitors, including cyclosporine $A$ and Valspodar ${ }^{[30]}$. Verapamil has always been an absolute standard P-gp inhibitor, and it had been demonstrated to inhibit the expression of P-gp effectively. This study also proves the conclusion by flow cytometry and western blot. In this study, bidirectional transport of digoxin in Caco-2 cells was used to evaluate whether GE was a P-gp inhibitor. In the presence of verapamil or GE, the decrease of Papp(BL-AP) leads to the decrease of ER, which indicates that P-gp transport activity and bidirectional detection function of digoxin are inhibited (Table 1). Efflux assay of rho-123 also showed that GE could inhibit P-gp mediated efflux function (Fig. 5). On the other hand, GE could significantly inhibit the expression of P-gp on Caco-2 cells (Fig. 6). These results showed that GE 
was a P-gp inhibitor, just like verapamil. It is well known that P-gp was synthesized in endoplasmic reticulum. The $140 \mathrm{kDa}$ precursor protein was glycosylated to form a membrane protein with a molecular

weight of $170 \mathrm{kDa}$, and then modified in Golgi matrix and transported to the cell membrane ${ }^{[31]}$. Therefore, the decrease of surface expression suggests that GE may affect the transport of P-gp from endoplasmic reticulum to Caco-2 cell membrane. However, further work is needed to prove this.

\section{Conclusions}

The intestinal absorption of GE is complex, involving two processes, mainly passive diffusion and P-gp mediated active transportation. GE is a potential inhibitor of P-gp, which has a good inhibitory effect on the efflux function and expression of P-gp. This study provides useful information for the pharmacokinetic study of GE, clarifies the transport mechanism of GE and the role of P-gp, which is helpful to design efficient P-gp inhibitors by optimizing the structure.

\section{Ethics approval and consent to participate}

Clinical and animal experiments were not involved in this study, so there is no ethical approval.

\section{Consent to publish}

All authors approve the final version of the manuscript and its publication.

\section{Availability of data and materials}

All test data were determined by mean and standard deviation $(x \pm s)$. The data were analyzed by SPSS18.0 software and differences between groups were compared by one-way ANOVA and t-test. When $P<0.05$, it shows that there is a significant difference between the two groups.

\section{Competing interests}

The authors declare no conflicts of interest regarding the publication of this paper.

\section{Funding}

This work was supported by grants from the National Natural Science Foundation of China(Nos. 81073122,81473400 and 81874360 ). The funding sponsored the design and the experimental reagents of this study, data collection and analysis in this study is also funded.

\section{Authors' Contributions}

$\mathrm{YH} \mathrm{Bu}$ and $\mathrm{H}$ Wu participated in the research design. MH Sun assisted with the experiments. $\mathrm{H}$ Zhang, $\mathrm{R}$ Deng and $\mathrm{Y}$ Wang performed the experiments, analyzed the raw data, and $\mathrm{YH}$ Bu wrote the manuscript. All authors approve the final version of the manuscript. 
Acknowledgements

The authors are very grateful to $\mathrm{H} \mathrm{Wu}, \mathrm{MH}$ Sun, $\mathrm{H}$ Zhang, $\mathrm{R}$ Deng and $\mathrm{Y}$ Wang for their experiments assistance. Platform support provided by Anhui University of Chinese Medicine.

\section{Abbreviations}

GE: Geniposide; P-gp: P-glycoprotein; rho-123: rhodamine-123; AP: the apical of transwell chamber; BL: the basolateral of transwell chamber; DDI: drug-drug interaction; Caco-2: the human colon adenocarcinoma cell line; MRP2: multidrug resistance associated protein; TEER: transepithelial electrical resistance; AKP: Alkaline phosphatase ; Papp: The apparent permeability coefficient; ER: the efflux ratio; PVDF: Polyvinylidene difluoride; SDS-PAGE: Sodium dodecyl sulfatepolyacrylamide gel electrophoresis; AA: adjuvant-induced arthritis; RA: rheumatoid arthritis

\section{Declarations}

\section{Ethics approval and consent to participate}

Clinical and animal experiments were not involved in this study, so there is no ethical approval.

\section{Consent to publish}

All authors approve the final version of the manuscript and its publication.

\section{Availability of data and materials}

All test data were determined by mean and standard deviation $(\mathrm{x} \pm \mathrm{s})$. The data were analyzed by SPSS18.0 software and differences between groups were compared by one-way ANOVA and t-test. When $\mathrm{P}<0.05$, it shows that there is a significant difference between the two groups.

\section{Competing interests}

The authors declare no conflicts of interest regarding the publication of this paper.

\section{Funding}

This work was supported by grants from the National Natural Science Foundation of China(Nos. 81073122,81473400 and 81874360 ). The funding sponsored the design and the experimental reagents of this study, data collection and analysis in this study is also funded.

\section{Authors' Contributions}

$\mathrm{YH} \mathrm{Bu}$ and $\mathrm{H}$ Wu participated in the research design. MH Sun assisted with the experiments. $\mathrm{H}$ Zhang, $\mathrm{R}$ Deng and $\mathrm{Y}$ Wang performed the experiments, analyzed the raw data, and $\mathrm{YH}$ Bu wrote the manuscript. 
All authors approve the final version of the manuscript.

\section{Acknowledgements}

The authors are very grateful to $\mathrm{H} \mathrm{Wu}, \mathrm{MH}$ Sun, $\mathrm{H}$ Zhang, $\mathrm{R}$ Deng and $\mathrm{Y}$ Wang for their experiments assistance. Platform support provided by Anhui University of Chinese Medicine.

\section{References}

1. Shan M, Yu S, Yan H, Guo S, Xiao W, Wang Z, Zhang L, Ding A, Wu Q, Li SFY. A Review on the Phytochemistry, Pharmacology, Pharmacokinetics and Toxicology of Geniposide, a Natural Product. Molecules. 2017;22:1689.

2. Li N, Li L, Wu H, Zhou H. Antioxidative Property and Molecular Mechanisms Underlying GeniposideMediated Therapeutic Effects in Diabetes Mellitus and Cardiovascular Disease. Oxid Med Cell Longev. 2019;2019:7480512.

3. Zhang C, Wang N, Tan HY, Guo W, Chen F, Zhong Z, Man K, Tsao SW, Lao L, Feng Y. Direct inhibition of the TLR4/MyD88 pathway by geniposide suppresses HIF-1a-independent VEGF expression and angiogenesis in hepatocellular carcinoma. Br J Pharmacol. 2020;177:3240-57.

4. Nicolas JM, Bouzom F, Hugues C, Ungell AL. Oral drug absorption in pediatrics: the intestinal wall, its developmental changes and current tools for predictions. Biopharm Drug Dispos. 2017;38:209-30.

5. Conde-Estévez D. Targeted cancer therapy: interactions with other medicines. Clin Transl Oncol. 2017;19:21-30.

6. Cheng S, Lin LC, Lin CH, Tsai TH. Comparative oral bioavailability of geniposide following oral administration of geniposide, Gardenia jasminoidestuEllis fruits extracts and Gardenia herbal formulation in rats. J Pharm Pharmacol. 2014;66:705-12.

7. Wang F, Cao J, Hao J, Liu K. Pharmacokinetics, bioavailability and tissue distribution of geniposide following intravenous and peroral administration to rats. Biopharm Drug Dispos. 2014;35:97-103.

8. Zakeri-Milani P, Valizadeh H. Intestinal transporters: enhanced absorption through P-glycoproteinrelated drug interactions. Expert Opin Drug Metab Toxicol. 2014;10:859-71.

9. Kiela PR, Ghishan FK. Physiology of Intestinal Absorption and Secretion. Best Pract Res Clin Gastroenterol. 2016;30:145-59.

10. Qian Z, Huang C, Shen C, Meng X, Chen Z, Hu T, Li Y, Li J. The permeability characteristics and interaction of the main components from Zhizi Bopi decoction in the MDCK cell model. Xenobiotica. 2016;46:733-42.

11. Wang Y, Jiang YM, Wang YT, Kang JW, Yu T, Zhao HY, Bian BL, Huang M, Bi HC. Inhibiton of cytochrome P450 isoenzymes and P-gp activity by multiple extracts of Huang-Lian-Jie-Du decoction. J Ethnopharmacol. 2014;156:175-81.

12. Peng Y, Yadava P, Heikkinen AT, Parrott N, Railkar A. Applications of a 7-day Caco-2 cell model in drug discovery and development. Eur J Pharm Sci. 2014;56:120-30. 
13. Tocchetti GN, Domínguez CJ, Zecchinati F, Arana MR, Ruiz ML, Villanueva S, Mottino AD, Weiss J, Rigalli JP. Inhibition of multidrug resistance-associated protein 2 (MRP2) activity by the contraceptive nomegestrol acetate in HepG2 and Caco-2 cells. Eur J Pharm Sci. 2018;122:205-13.

14. Joshi P, Vishwakarma RA, Bharate SB. Natural alkaloids as P-gp inhibitors for multidrug resistance reversal in cancer. Eur J Med Chem. 2017;138:273-92.

15. König J, Müller F, Fromm MF. Transporters and drug-drug interactions: important determinants of drug disposition and effects. Pharmacol Rev. 2013;65:944-66.

16. Barve A, Kovacs SJ, Ke J, Crabbe R, Grosgurin P, Menetrey A, Nicolas-Métral V, Dabovic K, Dole K, Zhang J, Praestgaard J, Sunkara G, Stein D. The effects of CYP3A4 induction and inhibition on the pharmacokinetics of alisporivir in humans. Clin Pharmacol Drug Dev. 2015;4:25-32.

17. Chen S, Einspanier R, Schoen J. Transepithelial electrical resistance (TEER): a functional parameter to monitor the quality of oviduct epithelial cells cultured on filter supports. Histochem Cell Biol. 2015;144:509-15.

18. Natoli M, Leoni BD, D'Agnano I, Zucco F, Felsani A. Good Caco-2 cell culture practices. Toxicol In Vitro. 2012;26:1243-6.

19. van Breemen RB, Li Y. Caco-2 cell permeability assays to measure drug absorption. Expert Opin Drug Metab Toxicol. 2005;1:175-85.

20. Hubatsch I, Ragnarsson EG, Artursson P. Determination of drug permeability and prediction of drug absorption in Caco-2 monolayers. Nat Protoc. 2007;2:2111-9.

21. Wang XX, Liu GY, Yang YF, Wu XW, Xu W, Yang XW. Intestinal Absorption of Triterpenoids and Flavonoids from Glycyrrhizae radix et rhizoma in the Human Caco-2 Monolayer Cell Model. Molecules. 2017;22:1627.

22. Wu J, Lin N, Li F, Zhang G, He S, Zhu Y, Ou R, Li N, Liu S, Feng L, Liu L, Liu Z, Lu L. Induction of Pglycoprotein expression and activity by Aconitum alkaloids: Implication for clinical drug-drug interactions. Sci Rep. 2016;6:25343.

23. de Castro WV, Mertens-Talcott S, Derendorf H, Butterweck V. Grapefruit juice-drug interactions: Grapefruit juice and its components inhibit P-glycoprotein (ABCB1) mediated transport of talinolol in Caco-2 cells. J Pharm Sci. 2007;96:2808-17.

24. Hansen TS, Nilsen OG. Echinacea purpurea and P-glycoprotein drug transport in Caco-2 cells. Phytother Res. 2009;23:86-91.

25. Yee S. In vitro permeability across Caco-2 cells (colonic) can predict in vivo (small intestinal) absorption in man-fact or myth. Pharm Res. 1997;14:763-6.

26. Volpe DA. Transporter assays as useful in vitro tools in drug discovery and development. Expert Opin Drug Discov. 2016;11:91-103.

27. Choi YH, Yu AM. ABC transporters in multidrug resistance and pharmacokinetics, and strategies for drug development. Curr Pharm Des. 2014;20:793-807. 
28. Lutz JD, Kirby BJ, Wang L, Song Q, Ling J, Massetto B, Worth A, Kearney BP, Mathias A. Cytochrome P450 3A Induction Predicts P-glycoprotein Induction; Part 2: Prediction of Decreased Substrate Exposure After Rifabutin or Carbamazepine. Clin Pharmacol Ther. 2018;104:1191-8.

29. Li H, Wu H, Shen C, Chen JY, Hu SL, Wu H. Comparative pharmacokinetics study after oral administration of geniposide in normal rats and adjuvant-induced arthritis rats by UPLC-MS/MS. Basic Clin Pharmacol Toxicol. 2013;113:294-9.

30. Li M, de Graaf IA, de Jager MH, Groothuis GM. Rat precision-cut intestinal slices to study P-gp activity and the potency of its inhibitors ex vivo. Toxicol In Vitro. 2015;29:1070-8.

31. Fu D, Arias IM. Intracellular trafficking of P-glycoprotein. Int J Biochem Cell Biol. 2012;44:461-4.

\section{Tables}

Tab.1 The effect of GE and verapamil on the bidirectional transport of P-gp substrate digoxin $\operatorname{across~Caco-2}(\bar{x} \pm s, n=3)$

\begin{tabular}{|llll|}
\hline \multirow{2}{*}{ Groups } & \multicolumn{2}{l}{ Papp $/ \times 10^{-6} \mathrm{~cm} \cdot \mathrm{s}^{-1}$} & \\
\cline { 2 - 3 } & AP-BL & \multicolumn{1}{l|}{ BL-AP } & ER \\
\hline Digoxin $(10 \mu \mathrm{M})$ & $4.61 \pm 0.02$ & $15.66 \pm 0.06$ & 3.40 \\
\hline Digoxin $(10 \mu \mathrm{M})+$ Verapamil $(100 \mu \mathrm{M})$ & $5.54 \pm 0.10$ & $7.55 \pm 0.09^{*}$ & $1.36^{* *}$ \\
\hline Digoxin $(10 \mu \mathrm{M})+\mathrm{GE}\left(25 \mu \mathrm{g} \cdot \mathrm{mL}^{-1}\right)$ & $5.63 \pm 0.13$ & $8.84 \pm 0.21^{*}$ & $1.57^{* *}$ \\
\hline Digoxin $(10 \mu \mathrm{M})+\mathrm{GE}\left(50 \mu \mathrm{g} \cdot \mathrm{mL}^{-1}\right)$ & $5.66 \pm 0.09$ & $9.00 \pm 0.10^{* *}$ & $1.59^{* *}$ \\
\hline Digoxin $(10 \mu \mathrm{M})+\mathrm{GE}\left(100 \mu \mathrm{g} \cdot \mathrm{mL}^{-1}\right)$ & $5.63 \pm 0.11$ & $8.22 \pm 0.08^{*}$ & $1.46^{* *}$ \\
\hline
\end{tabular}

${ }^{\star} P<0.05,{ }^{*} P<0.01$ vs. Papp (AP-BL), ${ }^{*} P<0.01$ vs. The ER of digoxin $(10 \mu \mathrm{M})$

\section{Figures}




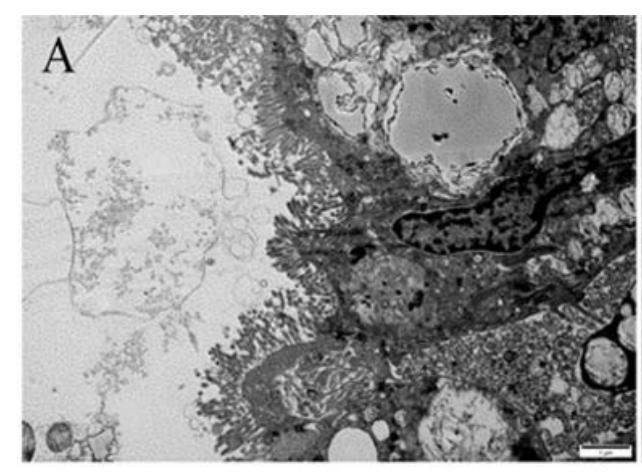

$\mathrm{D}$

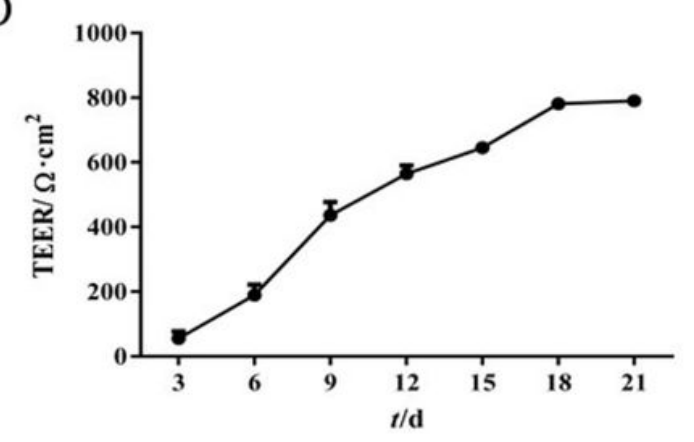

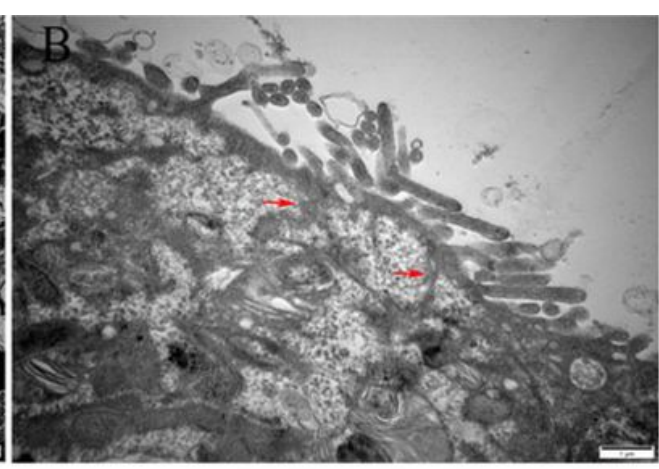

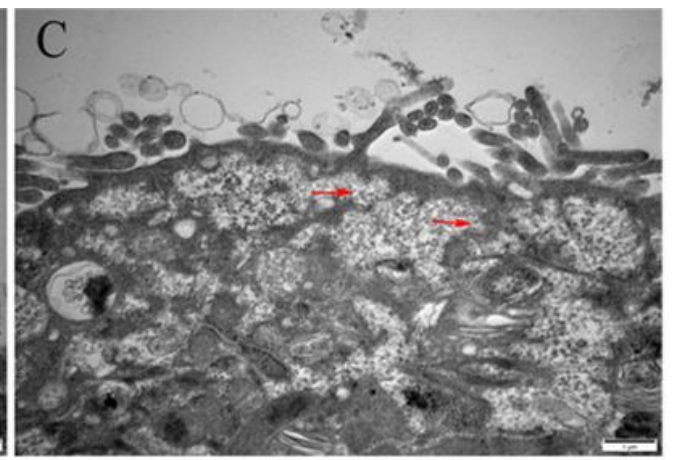

$\mathrm{E}$

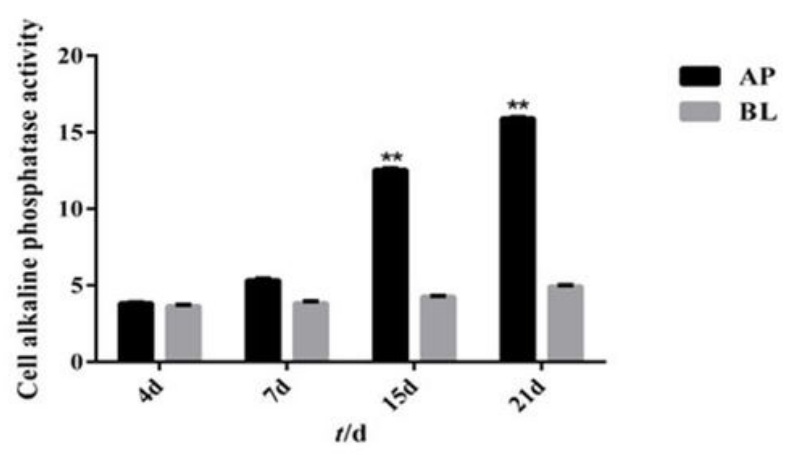

Figure 1

Evaluation of cell monolayer by cell morphology, TEER and cell polarity (A, B, C) Cell monolayer under transmission electron microscopy (Bar=1 $\mu \mathrm{m}$ ); (D) The TEER of Caco-2 cells from 3 to 21d; (E) AKP activity on both sides of the cell monolayer at $4,7,15,21 \mathrm{~d}$. ${ }^{*} \mathrm{P}<0.01 \mathrm{vs}$. AKP activity at $4 \mathrm{~d}$.
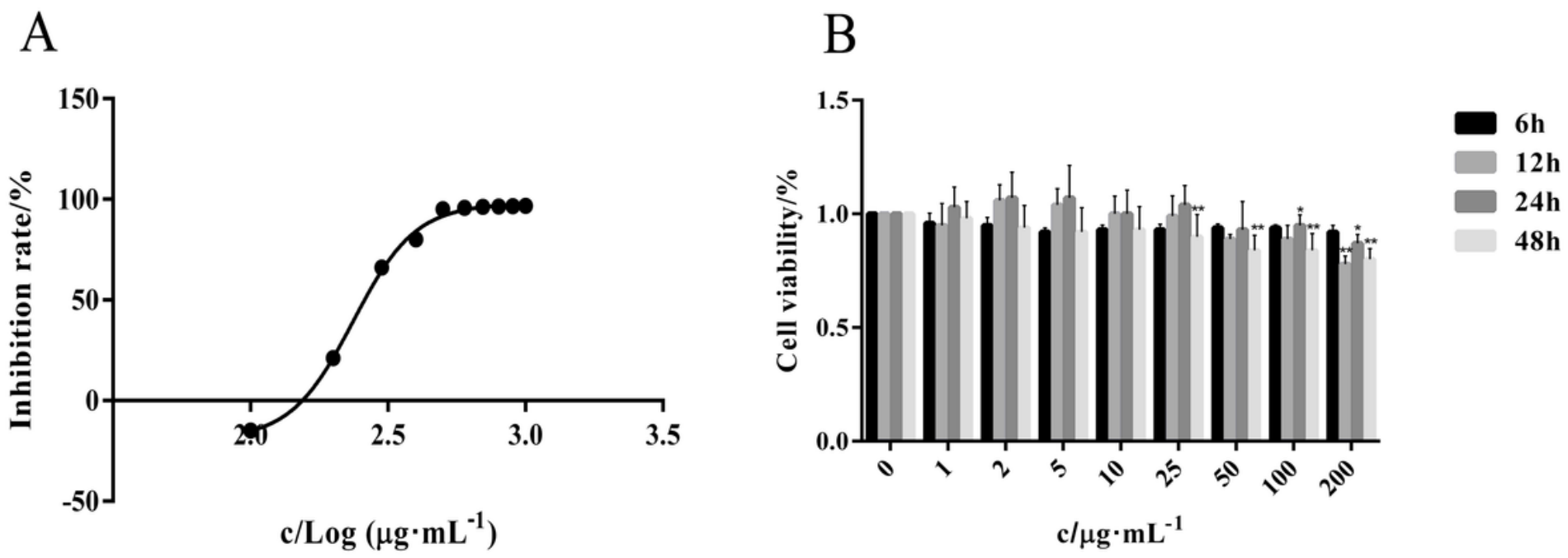

Figure 2

Cytotoxicity assay of Caco-2 cells by MTT (A) Determination of IC50 in Caco-2 cells; (B) Cell viability of different concentrations of GE at different times $(n=6) .{ }^{*} P<0.05, * * P<0.01$ vs. control. 
A

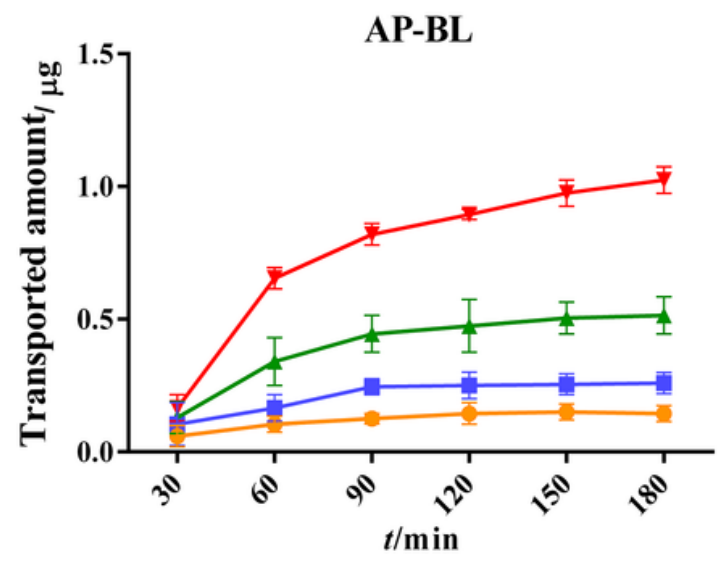

B

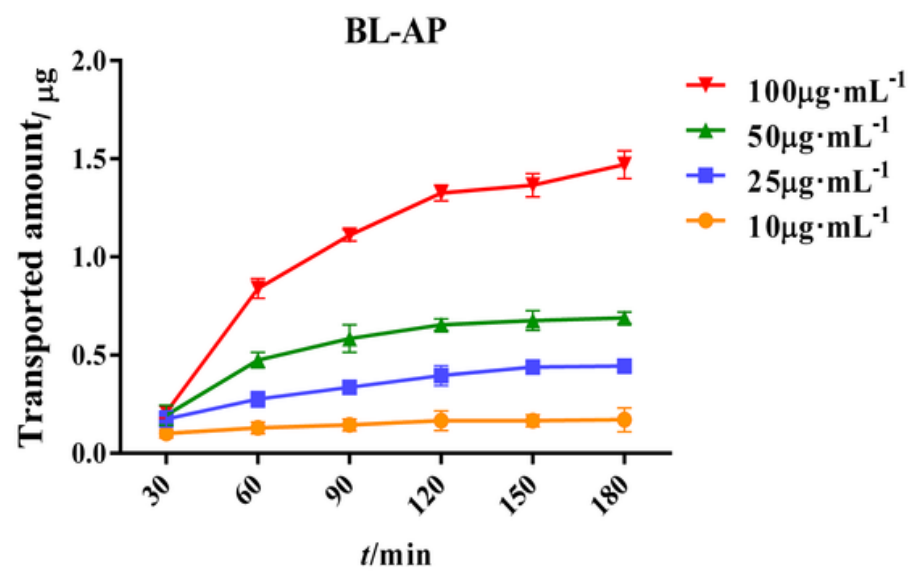

$\mathrm{C}$

Apparent permeabilitycoefficient of bidirectional transport of GE with different

\begin{tabular}{|c|c|c|c|}
\hline \multirow{2}{*}{$\begin{array}{c}\text { Concrentration } \\
/ \mu \mathrm{g} \cdot \mathrm{mL}^{-1}\end{array}$} & \multicolumn{2}{|c|}{$P$ app $/ \times 10^{-6} \mathrm{~cm} \cdot \mathrm{s}^{-1}$} & \multirow{2}{*}{ ER } \\
\hline & AP-BL & $\mathrm{BL}-\mathrm{AP}$ & \\
\hline 10 & $1.89 \pm 0.03$ & $3.15 \pm 0.07^{\circ}$ & 1.67 \\
\hline 25 & $2.03 \pm 0.08$ & $3.77 \pm 0.08^{\bullet}$ & 1.86 \\
\hline 50 & $2.16 \pm 0.09$ & $3.91 \pm 0.09^{*}$ & 1.81 \\
\hline 100 & $2.46 \pm 0.05$ & $4.59 \pm 0.06^{\bullet}$ & 1.87 \\
\hline
\end{tabular}

\section{Figure 3}

Transport experiments of GE at different time and concentration (A) GE transport from AP-BL at different times; (B) GE transport from BL-AP at different times; (C) The Papp of bidirectional transport of GE with different concentrations $(n=3)$. ${ }^{*}<<0.05$ vs. Papp (AP-BL). 
A

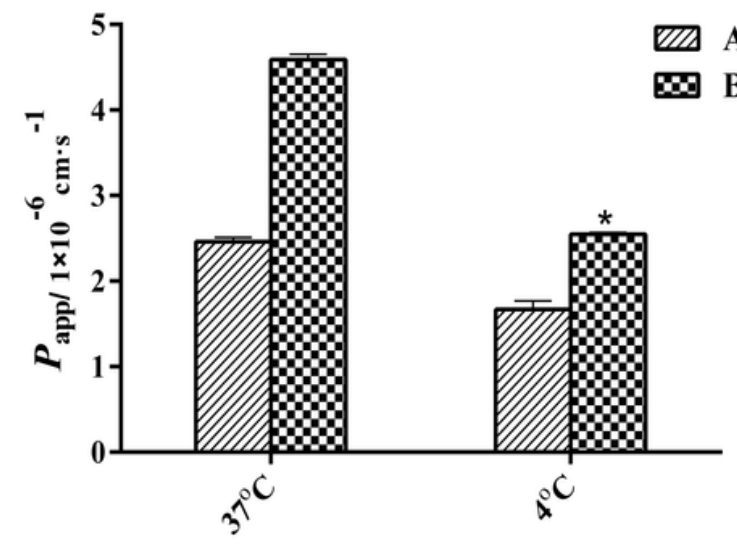

B

AP-BL

BL-AP

Effect of P-gp inhubitor on $\mathrm{GE}$ transport $(\bar{x} \pm, n=3)$

\begin{tabular}{|c|c|c|c|}
\hline \multirow{2}{*}{ Groups } & \multicolumn{2}{|c|}{$P_{\mathrm{qpp}} / 10^{-4} \mathrm{~cm} \cdot \mathrm{s}^{-1}$} & \multirow{2}{*}{ ER } \\
\hline & AP-BL & BL-AP & \\
\hline $\mathrm{GE}\left(100 \mu \mathrm{g} \cdot \mathrm{mL} \mathrm{L}^{-1}\right)$ & $2.46 \pm 0.05$ & $4.59 \pm 0.06$ & 1.87 \\
\hline $\mathrm{GE}(100 \mu \mathrm{g} \cdot \mathrm{mL} \cdot 1)+\mathrm{Veraparil}(100 \mu \mathrm{M})$ & $2.84 \pm 0.08$ & $1.75 \pm 0.11^{\circ}$ & $0.62^{\circ}$ \\
\hline
\end{tabular}

\section{Figure 4}

Transport experiments of GE at different temperature and in the presence of verapamil (A) Effect of temperature on GE transport ( $n=3) .{ }^{*} \mathrm{P}<0.05$ vs. $37^{\circ} \mathrm{C}$ Papp (BL-AP); (B) Effect of verapamil on GE transport $(n=3) .{ }^{*} \mathrm{P}<0.05$ vs. Papp (GE group). 


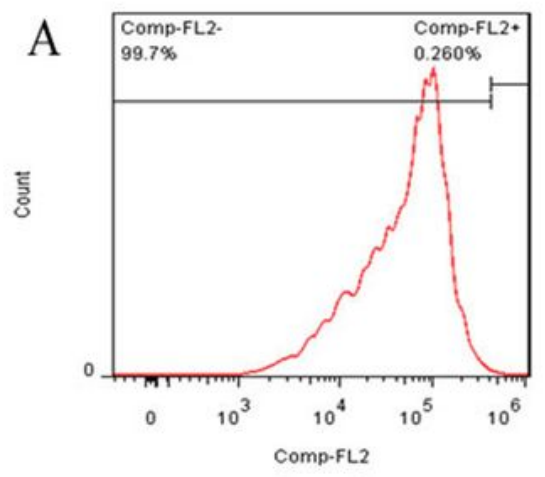

Control

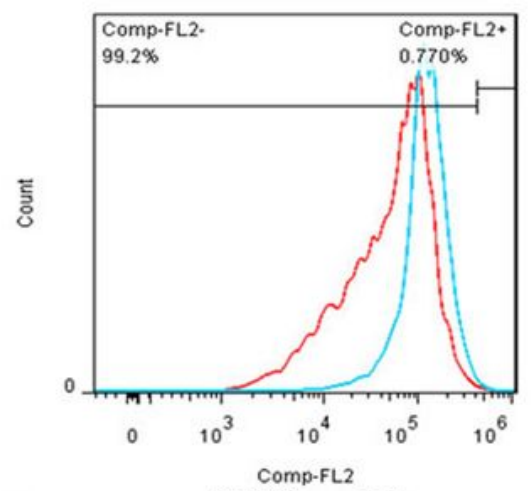

B

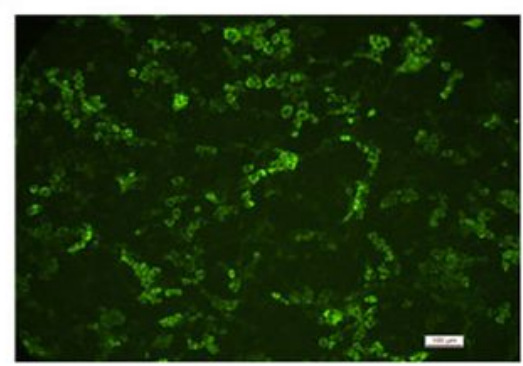

Control

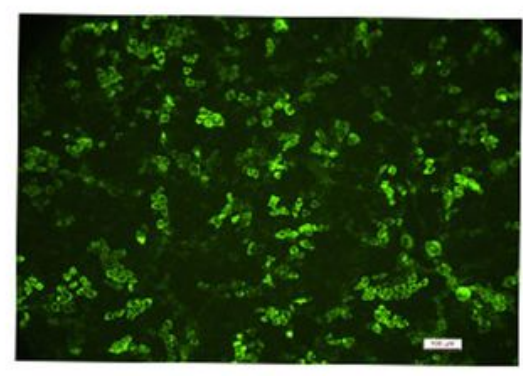

$\mathrm{GE}\left(50 \mu \mathrm{g} \cdot \mathrm{mL}^{-1}\right)$

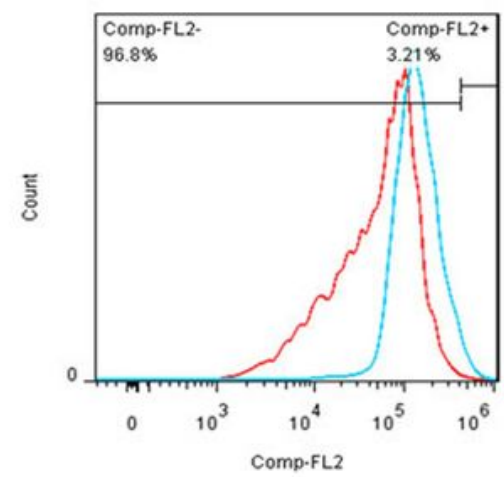

Verapamil

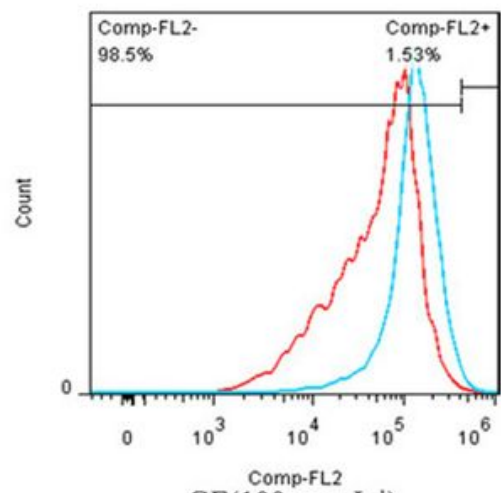

$\mathrm{GE}\left(100 \mu \mathrm{g} \cdot \mathrm{mL}^{-1}\right)$

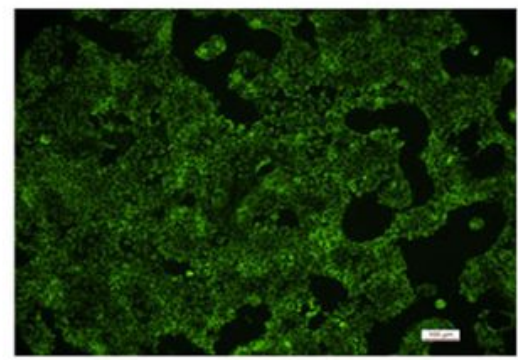

Verapamil

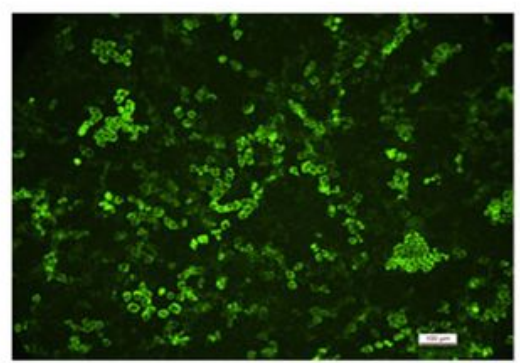

$\mathrm{GE}\left(100 \mu \mathrm{g} \cdot \mathrm{mL}^{-1}\right)$

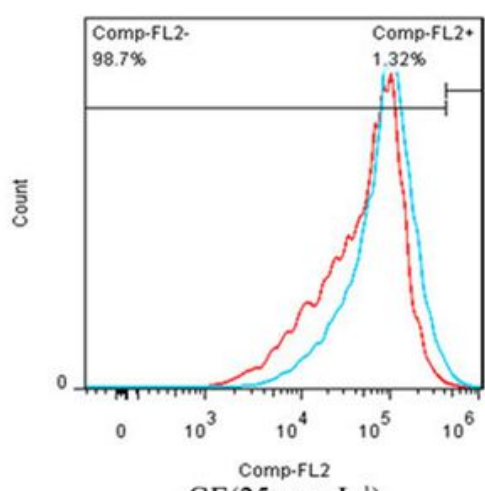

$\mathrm{GE}\left(25 \mu \mathrm{g} \cdot \mathrm{mL}^{-1}\right)$
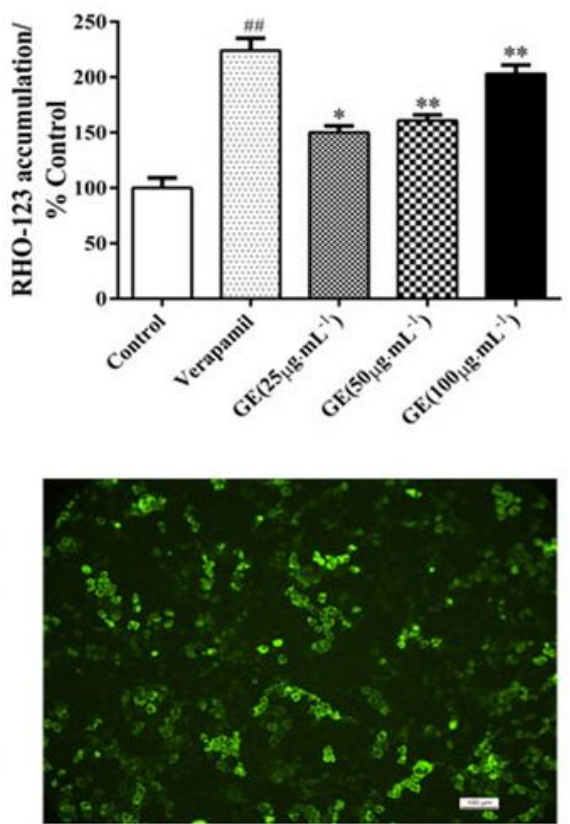

$\mathrm{GE}\left(25 \mu \mathrm{g} \cdot \mathrm{mL}^{-1}\right)$

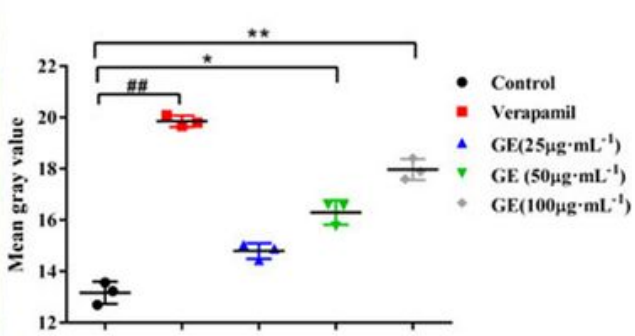

\section{Figure 5}

P-gp function analysis by flow cytometry and immunofluorescence (A) P-gp function analysis by flow cytometry using rho-123. (B) P-gp function analysis by immunofluorescence using rho-123 ( $n=3)$. ${ }^{\star} \mathrm{P}<0.05,{ }^{\star *} \mathrm{P}<0.01, \# \# \mathrm{P}<0.01$ vs. control. 

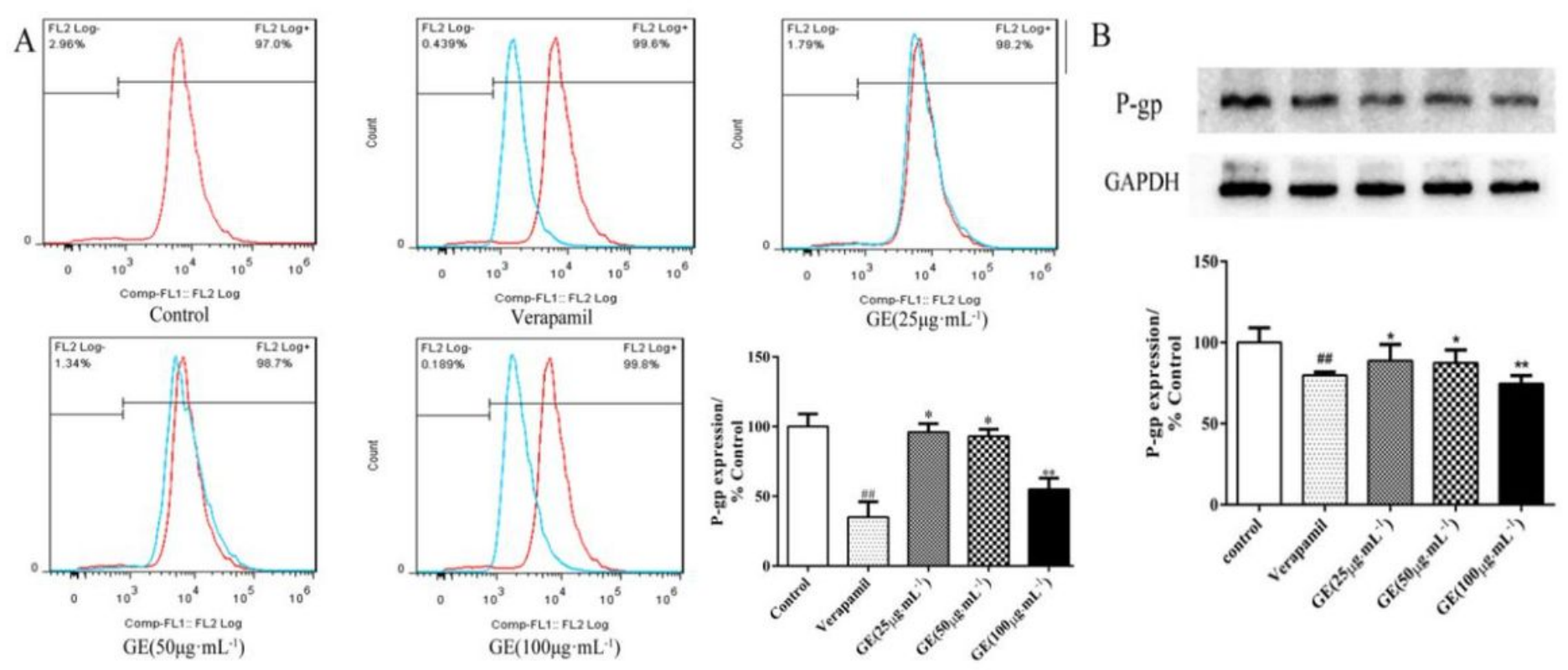

Figure 6

P-gp expression analysis by flow cytometry and Western blot (A) P-gp expression analysis by flow cytometry; (B) P-gp expression analysis by Western blot $(n=3) * P<0.05,{ }^{*} P<0.01, \# \# P<0.01$ vs. control. 